\title{
REFLEXIONES EN TORNO AL TRATAMIENTO DE LA DIVERSIDAD CULTURAL EN ESCUELAS RURALES DEL CONURBANO BONAERENSE
}

\author{
M. Eugenia TARUSELLI*
}

\section{Resumen}

En la actualidad -en contraposición al viejo modelo escolar que proponía homogeneizar a los estudiantes-, nos encontramos con un paradigma que sostiene el valor de incorporar la diversidad cultural. No obstante, en la cotidianidad escolar conviven y se tensionan, de forma compleja, discursos y prácticas pertenecientes a ambos modelos. Así, este artículo se propone indagar algunas de esas tensiones a partir de una investigación llevada a cabo en escuelas rurales del conurbano bonaerense.

Palabras clave: Escuela- Paradigmas educativos- Diversidad cultural- HomogeneidadConstrucciones identitarias-

\begin{abstract}
Nowadays, in contrast with the old school model that aimed at homogenising students, we are faced with a paradigm that aims at focusing on the importance of incorporating cultural diversity. Nonetheless, in the school routine, discourses and practices pertaining to both models coexist and become tense. Thus, this article aims at investigating some of these tensions, through a research done in rural schools situated in the conurbation of the province of Buenos Aires.
\end{abstract}

Key words: School-Educational paradigms-Cultural diversity-Homogeneity- Identity constructions-

\section{Résumé}

Dans l'actualité -en opposition avec le vieux modèle scolaire qui a proposé d'homogénéiser les étudiants- nous nous trouvons avec un modèle qui soutient la valeur d'incorporer la diversité culturelle. Néanmoins, chaque jour scolaire cohabitent de manière complexe, discours et practiques appartenant aux deux modèles. Ainsi, cet article se propose de rechercher quelques unes de ces tensions à partir d' une enquête réalisée dans les écoles de la banlieue de Buenos Aires.

Mots clé: École- Modèle éducatif- Diversité culturelle- Homogénéité- Constructions d'identité-

\footnotetext{
*Licenciada y profesora en Ciencias Antropológicas. Becaria doctoral en antropología por la Universidad de Buenos Aires. e-mail: me.taruselli@gmail.com
}

Fecha de recepción del artículo: Octubre 2017

Fecha de evaluación: Noviembre 2017 


\section{Introducción}

Durante el siglo XIX, fue requisito para la construcción del Estado Argentino, la afirmación de una identidad nacional (caracterizada por un pueblo asociado a un territorio y portador de una única lengua y cultura) frente a un "otro" negativo, el cual se conformó entorno a los indígenas (Hecht, 2007). Las políticas homogeneizadoras en educación, características de ese periodo, contribuyeron a la conformación de aquella identidad nacional y, en el marco "igualador" que proponía la Ley de Educación No 1420 (1884) o la ya derogada Constitución Nacional de 1853, se negaron las especificidades lingüísticas y culturales (Hecht, 2007, 2013). La creación del sistema educativo en Argentina -influenciado por el positivismo y el evolucionismo- tuvo como objetivo principal eliminar los aportes de aquellas culturas consideradas bárbaras y simples (Sinisi, 1999).

En la actualidad, en contraposición, nos encontramos con un nuevo paradigma sobre la educación escolar que plantea la importancia de valorar la diversidad cultural, incorporando distintos saberes y formas de estar, ver e interpretar el mundo. Así, luego de diversos estadios por los cuales transcurrió la educación argentina ${ }^{1}$, en 2006 se aprueba la Ley de Educación Nacional $N^{\circ} 26.206$ que establece, entre otras, la Modalidad de Educación Intercultural Bilingüe (en adelante EIB).

Si bien en el desarrollo del escrito de esta Ley se plantea en reiteradas oportunidades el "respeto por la diversidad cultural" como un valor a adoptar desde la escuela, también se asocia esta idea directamente con los pueblos indígenas ${ }^{2} \mathrm{y}$, al mismo tiempo, sólo se menciona el concepto de interculturalidad cuando se hace referencia a la Modalidad de EIB, la cual también se encuentra dirigida a los pueblos originarios. De esta manera, se maneja una noción de interculturalidad que tiene como actor central sólo a aquellos portadores de marcas étnicas de otredad y, en este sentido, la misma implicaría una relación con otros no marcados étnicamente (García Palacios, Hecht, Enriz, 2015). Asimismo, en varias oportunidades, aquellas relaciones se encuentran mediadas por discursos esencialistas y ahistóricos con respecto a la mirada que se tiene sobre los "otros" (Novaro, 1999 en Diez 2004), otorgándole a los mismos, identidades estáticas que supuestamente comparten para ser quienes son.

Ahora bien, este trabajo se enmarca en los avances de mi proyecto de doctorado ${ }^{3}$, cuya investigación se lleva a cabo en escuelas rurales ubicadas en la zona oeste del conurbano de la provincia de Buenos Aires. En esta ocasión, me propongo documentar y analizar de qué forma se aborda y trata la diversidad cultural presente en las aulas de dichas instituciones. Para esta tarea, la metodología de investigación se basará en un abordaje antropológico desde un enfoque etnográfico, con el fin de "documentar lo no documentado de la realidad social" (Rockwell, 2009). Al mismo tiempo, retomaré diversos aportes teóricos del campo de la antropología educativa en contextos interculturales, que me permitirán realizar un análisis pertinente de los datos obtenidos durante mi trabajo de campo.

Así, el artículo primeramente expone ciertas cuestiones metodológicas y contextuales para situar al lector, para luego avanzar -en tres apartados diferentes- sobre el análisis de los tratamientos en torno a la diversidad cultural que se han relevado en las escuelas estudiadas. Por último, las reflexiones finales no se presentan a modo de conclusiones acabadas, sino como el producto de

\footnotetext{
${ }^{1}$ Para ampliar acerca de las transformaciones de las políticas educativas en Argentina, ver Thisted 2014.

2 "Capítulo II, Artículo 92: Formarán parte de los contenidos curriculares comunes a todas las jurisdicciones: (...) e) El conocimiento de la diversidad cultural de los pueblos indígenas y sus derechos, en concordancia con el artículo 54 de la presente ley".

${ }^{3} \mathrm{Mi}$ proyecto de doctorado se titula "Biografías escolares y diversidad etnolingüística: un estudio sobre el paso entre niveles (jardín, primario y secundario) de niños y jóvenes tobas, migrantes y criollos en el Conurbano Bonaerense". El mismo está dirigido por la Dra. Ana Carolina Hecht y se encuentra financiado por la Universidad de Buenos Aires a través de una beca de posgrado que cuenta con la dirección de la Dra. María Cristina Messineo.
} 
un pensamiento en proceso y como base de futuras reflexiones e interrogantes sobre el abordaje de la diversidad cultural en las aulas.

\section{Breve contextualización y notas sobre el trabajo de campo}

Como anticipamos, esta investigación se lleva adelante en tres escuelas rurales que representan cada nivel educativo: inicial, primario y secundario. Las mismas -ubicadas en la zona oeste del Conurbano Bonaerense-, se encuentran en un barrio que presenta una gran diversidad cultural al estar conformado por vecinos y vecinas de origen boliviano, paraguayo, de distintas provincias del interior de Argentina y población oriunda del lugar desde hace generaciones. Además, a estas instituciones asisten estudiantes provenientes de una comunidad toba que se encuentra a unos $2 \mathrm{~km}$ del lugar. Estas escuelas se insertan en un contexto sociocultural complejo al recibir niños/as y jóvenes que se diferencian entre sí por sus identificaciones étnicas y nacionales pero que, simultáneamente, comparten las mismas necesidades materiales y exclusión social.

En este trabajo, sólo nos centramos en el análisis de los datos obtenidos en la escuela primaria y secundaria en los periodos que van de 2012 a 2014 -momento en el cual realicé mi tesis de licenciatura ${ }^{4}$ y únicamente trabajé en la primaria- y de 2015 hasta la actualidad. La recolección de los mismos se llevó a cabo a través del trabajo de campo que implicó: entrevistas formales con docentes, directivos, estudiantes y madres de familias; charlas informales con los mismos actores en diferentes espacios del barrio; observación de clases, actos escolares y recreos; y revisión de material documental de las escuelas (proyectos institucionales, proyectos áulicos, carpetas y cuadernos de los estudiantes). En total, se realizaron ochenta y tres visitas al campo, en las cuales pude atender lo que sucedía en cada contexto así como el sentido que eso tenía para quienes estaban involucrados (Szulc et al, 2009).

Finalmente, es necesario aclarar que las reflexiones expuestas en este artículo, al formar parte de una investigación doctoral en curso, presentan un diseño metodológico el cual está en constante redefinición según los imponderables que acontecen en el campo.

\section{Abordajes de la diversidad cultural en el aula}

Durante el trabajo de campo realizado, algunos/as docentes han dejado de trabajar en las escuelas donde llevo adelante esta investigación, sin embargo, muchos/as continúan en sus puestos. En estos años, se pudieron relevar en las instituciones matices y voces contrapuestas a la hora de pensar y actuar sobre la realidad de las aulas. Esto generaba un entramado de discursos y prácticas, con respecto a la diversidad cultural, que interactuaban de forma compleja entrando en tensión continuamente. Así, algunos abordajes observados entorno la diversidad cultural -en los cuales me enfocaré en este artículo- tuvieron que ver con: 1)- un señalamiento/exposición de ciertos estudiantes como forma de normalizar o aceptar la diversidad cultural; 2)- una mirada esencializadora y ahistórica sobre la identidad étnica y; 3)un tratamiento folklorizado o inexistente -este último asociado a la idea de homogeneidad estudiantil-, de los saberes y experiencias extraescolares de los niños, niñas y jóvenes.

Así, podemos decir que en la cotidianeidad escolar se dan algunas formas de ver, pensar y actuar en relación con la diversidad cultural que coinciden entre sí tratando de enmarcarse -a su manera- en el paradigma educativo contemporáneo; y otras que parecen filtrarse como resabios del tradicional modelo que pretende dejarse atrás.

\footnotetext{
${ }^{4}$ Titulada "Escolarización en contextos de diversidad lingüístico-cultural: un estudio etnográfico sobre una escuela rural de la provincia de Buenos Aires donde asisten niños tobas (qom), migrantes bolivianos e hijos de migrantes bolivianos". Dirigida por la Dra. Ana Carolina Hecht y codirigida por la Dra. María Cristina Messineo. Facultad de Filosofía y Letras, UBA.
} 
A continuación, analizaremos estas formas de tratamiento que se dan al interior de estas escuelas, sin por ello pretender realizar un trabajo comparativo ni absolutizador del trabajo docente. Tan solo se trata de establecer ciertas generalizaciones con fines analíticos para comprender la complejidad cotidiana de las instituciones en las que se desarrolló este trabajo.

\subsection{El señalamiento como forma de normalizar la otredad}

Muchos jóvenes del barrio, sobre todos los bolivianos ${ }^{5}$, transitan experiencias migratorias -ya sea la propia como la de miembros de su familia- desde muy pequeños $\mathrm{y}$, a medida que pasan los años y van creciendo, en líneas generales, se observa que sus deseos de hablar acerca de sus orígenes son cada vez menores. Es así que, cuando llegan a la escuela secundaria, no hablan al respecto a no ser que un adulto les pregunte directamente sobre el tema (Taruselli, 2017, inédito)

Esta diferencia entre los niños de la primaria y los jóvenes de la secundaria, quizás esté relacionada con el hecho de que los más grandes comienzan a vivenciar de forma más cotidiana, como sostiene Novaro (2011), tensiones muy claras de sus adultos de referencia en torno a cuestiones identitarias. Esto se desarrolla en un contexto social en el que se registran imágenes negativas sobre las migraciones recientes de países limítrofes (Novaro, 2011). Al igual que otros inmigrantes intra-regionales, los bolivianos presentan el estigma de ser "inmigrantes no deseados" al definírselos como símbolos del atraso y subdesarrollo del que Argentina emergió gracias a los inmigrantes transatlánticos que permitieron civilizar la nación a fines del siglo XIX (Gavazzo, 2013). En este sentido, la palabra "boliviano" muchas veces es utilizada de un modo peyorativo, como insulto.

Así, situaciones de discriminación que hayan sufrido estos chicos y chicas o sus padres, pueden generar rechazo o negación ante la sola idea de revelar sus orígenes. En muchos casos, este ocultamiento puede ser visto como una "estrategia de supervivencia" o de prevención ante ciertos contextos que pueden ser hostiles y violentos ante su presencia, considerándolos parte de grupos raciales inferiores. En este sentido, Balibar considera el racismo como un fenómeno social que se observa en prácticas, discursos y representaciones productos de la necesidad de preservar la identidad del "nosotros" ante cualquier perspectiva de mestizaje. Los mismos, funcionan en una red de estereotipos que permiten la formación de una comunidad racista y obligan a los individuos y colectividades que son objeto de ese racismo a percibirse también como una comunidad (1990). Como sostiene Paulo Freire:

"El dominante necesita inculcar al dominado una actitud negativa hacia su propia cultura. Los primeros favorecen en los últimos el rechazo de la propia cultura, generándoles la falsa comprensión de la misma como algo desagradable e inferior (...)" (Freire, 1985 en Rebellato 2010:51)

Por este motivo, aquel "preguntar" de los docentes -motivado por el simple hecho de la curiosidad o la buena intención de conocer a los estudiantes-, inesperadamente puede tornase estigmatizante y el deseo de dar lugar a las voces de los niños/as y jóvenes puede devenir en un

\footnotetext{
${ }^{5}$ Las familias bolivianas del barrio trabajan en la costura, tejido y bordado de prendas, en los hornos de ladrillo y en las quintas hortícolas que se encuentran en los alrededores de las escuelas. Muchas de ellas, se separan por la migración quedando algunos miembros en Bolivia y otros en Argentina. También se dan situaciones en las cuales parte de la familia retorna a Bolivia por un tiempo determinado y luego regresan al barrio. Los niños y jóvenes, acompañan en muchas ocasiones este continuo fluir entre países, obligándolos a cursar sus estudios en diferentes instituciones escolares donde cambian no sólo los contenidos sino las dinámicas dentro de cada una. Al respecto, Diez y Novaro realizaron un trabajo acerca de las continuidades y discontinuidades que se dan entre el sistema educativo en Bolivia y en Argentina (2014)
} 
señalamiento de los "otros", quienes en muchas ocasiones, no quieren ser identificados por su origen por temor a futuros actos de señalamiento y discriminación.

Veamos a continuación unas notas de campo que muestran cómo algunos sentidos en torno a "lo boliviano" adquieren valoraciones negativas y (lo que creemos una consecuencia) la negación de estos jóvenes a ser identificados por su origen en ciertos contextos:

Situación: Clase de inglés en $2^{\circ}$ año de la secundaria

Uno de los estudiantes dice algo, que no logro escuchar, y otro le responde riéndose, de forma peyorativa y en voz un poco baja: ";callate boliviano!"' ( $\sin$ ser aquel de Bolivia). La profesora no dice nada, tampoco sé si el resto escuchó este comentario en forma de insulto. Sin embargo, sospecho que Luis ${ }^{7}$, un joven boliviano que se encuentra a mi lado sí lo hizo. Continúa la clase normalmente.

(Nota de campo, noviembre de 2015)

Situación: Clase de historia en $2^{\circ}$ año de la secundaria

Mientras la docente hablaba sobre los países limítrofes y la densidad de la población, pregunta:

Profesora:- “¿Son todos argentinos los que viven acá? ¿Luis, vos dónde naciste?

Luis: - Perú... (risas de sus compañeros)

Profesora: - ¿Perú? ¿Dónde naciste?

Luis: - No me acuerdo... (nervioso)

Profesora: - ¿Cómo que no te acordas?

Luis: - No me acuerdo...." (risas de sus compañeros)

El joven continúa diciendo con risa nerviosa que nació en Perú y tras las preguntas que la docente le fue haciendo, contó que no habla quechua pero que entiende. Luego le pregunta a Martín, su compañero de mesa:

Profesora: - “¿Vos Martín dónde naciste?

Martín: - Bolivia

Profesora: - ¿En qué lugar?

Martín: - Gran Chaco

Profesora: - ¿Por qué vinieron acá con tu mamá y tu papá?

Martín: - Por trabajo"

(...) Luego le pregunta a Santiago y este dice que nació en Argentina. Entonces la profesora señala que en la Argentina vive población nativa, como Santiago, y población extranjera como Luis y Martín (...). La profesora se vuelve a Luis nuevamente e insiste en que no puede ser que no sepa dónde nació. Le pregunta su documento y este no lo recuerda, le dice que para la próxima clase tiene que saber dónde nació y su $\mathrm{DNI}^{8}$.

(Nota de campo, octubre de 2015)

En relación con este último relato, las preguntas de la profesora eran rápidas, como si fuera un "ping-pong" de preguntas y respuestas en un juego; un ritmo de charla que puede variar entre comunidades de habla y puede llegar a ser incómodo para algunos jóvenes no sólo por la forma de las preguntas sino por el contenido. Al mismo tiempo, era claro que la docente deseaba "naturalizar" la diversidad de procedencias de los jóvenes, entendiendo que es algo normal hablar sobre eso y está bien que así sea. Sin embargo, Luis, al ser el primero en ser indagado, se mostró nervioso, reflejándolo en sus respuestas reiteradas que afirmaban no saber dónde había nacido.

Este mismo señalamiento se puede observar con los niños/as y jóvenes de la comunidad toba, tanto entre los estudiantes como por parte de los docentes:

Situación: Clase de literatura en $5^{\circ}$ año de la secundaria

\footnotetext{
${ }^{6} \mathrm{El}$ "entrecomillado y la cursiva" indican citas textuales de las personas.

${ }^{7}$ Los nombres de los niños/as, jóvenes y adultos han sido cambiados para resguardar su identidad.

${ }^{8}$ Documento Nacional de Identidad.
} 
La profesora se apoya contra la pared cerca de mí y de Julián que se encontraba en un pupitre frente mío. Entonces, de forma sorpresiva, ella levanta su mano, despliega su dedo índice y a la altura de la sien lo señala y me dice en voz alta: "ellos son los tobas". El nivel de cercanía entre los tres era demasiado - producto de la pequeñez del aula- y el dedo de la profesora literalmente quedó a unos pocos centímetros de la cabeza del joven. Julián se pone nervioso, se encoje de hombros y sonríe asintiendo (...).

(Nota de campo, marzo de 2016)

Si bien ambos casos relatados se dieron ante mi presencia, la cual quizás incitó a que esto suceda en pos de normalizar/naturalizar la diversidad; no debemos dejar de lado la idea que parece subyacer a este hecho: debemos aceptar la diversidad e incluirla en las aulas, lo cual puede interpretarse como "luz verde" para identificar públicamente a los "otros" y otorgarles identidades, suponiendo que estos así lo desean o adhieren a las mismas. El señalamiento, derivado de las buenas intenciones de querer naturalizar las diferencias para incluirlas en las aulas, puede tener resultados contrarios a los que se esperan cuando en verdad no sabemos si todos los estudiantes quieren ser señalados como diferentes (más aún en espacios institucionales donde muy recientemente se valora la diversidad) y cuando olvidamos que muchos "otros" no solo son diferentes sino que también se encuentran inmersos en situaciones de desigualdad. Es menester recordar que:

"nombrar al otro no es solo una forma de reconocerlo, sino que también puede ser una
forma de marcación en tanto un término (indio, hablante de lengua indígena, boliviano)
lleva asociado un significado peyorativo que se impone sobre alguien" (Novaro,
$2011: 188$ )

En este sentido, veamos cómo a través de una actividad que apelaba a la imaginación de los estudiantes, el término "aborigen" se carga de un fuerte sentido negativo, relacionándolo directamente con "lo sucio":

Situación: Clase de Ciencias sociales en $5^{\circ}$ grado de la primaria

Luego de charlar acerca de la conquista de América, la maestra le pregunta a los chicos: “ ¿si pudieran regalarle un objeto a un aborigen qué le regalarían?”. Inmediatamente, agrega qué le regalarían si tuvieran una máquina del tiempo y conocieran a los aborígenes de la época de Colón, ya que los aborígenes de ahora no necesitan nada dando a entender que conocen todo lo que ellos conocen. (...) Les propone que piensen algo que les sirva. Los chicos comienzan a postular sus ideas en voz alta y ella les va contestando: que para qué le van a regalar una calculadora, “¿qué cuenta van a sacar (los aborígenes)? "; que tampoco un plato, ellos no comían con plato y sino, se los hacían ellos mismos. Los chicos entonces piensan alternativas y comienzan a gritar: "un shampoo, un jabón en polvo, agua y jabón, un espejo y un peine”. La maestra se ríe. Mientras charlan sobre el tema, observo al curso y detecto que María Luna, una niña del barrio toba, se encuentra en silencio con un aspecto tenso y sus mejillas enrojecidas.

(Nota de campo, octubre de 2016)

Así, los estudiantes pueden encontrarse insertos en situaciones o contextos que ponen a prueba sus identificaciones o intentan definirlas. En este sentido, la escuela se despliega como un espacio en el cual, en ocasiones, en pos de una reivindicación de la diversidad se "recorta" a los sujetos cristalizando sus identidades con respecto a una única categoría de identificación (García Palacios, 2011) De esta manera, se genera un interjuego entre autoidentidad y heteroidentidad (Simon, 1979 en Cuche, 2007) el cual se torna complejo cuando se trata de niños y adolescentes que continuamente se encuentran buscando lugares de pertenencia e identificación entre pares. Finalmente, es necesario no dejar de ver que este señalamiento de las diferencias, también se da con relación a otras cuestiones y no solo en términos de los orígenes y de las identidades étniconacionales. Así, en ocasiones, los estudiantes pueden ser señalados o "etiquetados" de diferentes 
maneras (tanto positivas como negativas), por ejemplo en relación con lo que se creen que son sus capacidades y competencias. En este sentido, los niños/as y jóvenes se van reposicionando y actuando estratégica y deliberadamente, según las diferentes identificaciones que los demás construyen sobre ellos.

\title{
3.2 La mirada esencializadora de las identidades
}

El señalamiento de ciertos estudiantes y la consecuente designación de sus identidades, puede derivar en discursos que las esencializan y homogeneizan, quitándoles la capacidad histórica de transformarse, hecho que sucede especialmente con los estudiantes toba.

En el año 2007, a través de varias negociaciones con el Instituto Nacional de Asuntos Indígenas (INAI) y gracias a un subsidio del mismo para comprar tierras, se instaló en la zona a unas veinte cuadras de las escuelas, un barrio toba; ampliando más aún la diversidad en las aulas. La gente que conformó el barrio se autorreconocía como toba/qom y provenía de un asentamiento marginal próximo a la Ciudad Autónoma de Buenos Aires (CABA) que, a su vez, era fruto de la migración del Gran Chaco a Buenos Aires cercana a 1980. Este hecho no fue menor, ya que impactó de forma sorpresiva en una parte de la comunidad educativa, al no coincidir sus representaciones acerca de cómo, supuestamente, era o debía ser un indígena/toba, con la imagen y forma de vida que presentaban los miembros de la comunidad recién llegada a la zona:

\begin{abstract}
Investigadora: -"Vos estuviste cuando llegó la comunidad toba ¿Qué recordas de ese momento? ¿Qué se comentaba acá en la escuela?

Violeta: - Y... era como una situación rara porque era una mezcla de "bienvenida pero los queremos hasta ahi". (...) El hecho de que muchos venían de ****9 es como que era raro para los chicos de acá “¿Cómo? ¿Vienen grupos indígenas supuestamente, pero vienen de ****?”. Era como raro, era como que les costaba a los chicos de acá entender. (...)

Investigadora: - ¿Esto también se escuchaba entre los profesores?

Violeta: -Cuando dijeron que venía el barrio toba, nosotros lo primero que nos imaginamos "Bueno, vienen de allá de su territorio, vienen anda a saber en qué condiciones"... y resulta que la mayoría eran de **** (se ríe). Era raro para nosotros también hacernos la idea "¿Cómo, del Chaco a ****y de **** acá?"
\end{abstract}

(Entrevista a profesora, julio de 2017)

Durante charlas informales y entrevistas que tuve con algunos/as docentes de las escuelas, surgieron reflexiones (en ocasiones de forma espontánea y otras a partir de mis preguntas) que reflejaban ciertas inquietudes con respecto a la identidad étnica de los estudiantes tobas. El hecho de que muchos de ellos se hubiesen criado (y muchos nacido) en una villa cercana a CABA, era condición suficiente para dudar de aquella pertenencia étnica. Surgían por lo tanto, algunos discursos en los cuales se planteaba que: "de tobas no tienen nada"; "solo conservan el título"; "solo conservan lo artesanal"; "están desculturados"; "estos tobas son de ****..."; "los tobas viven en el barrio toba, son tobas porque viven ahí. Si vivieran en otro lado no serían tobas" $"$.

Al mismo tiempo, se hacía hincapié en que habían perdido ciertos elementos o rasgos de su cultura y adoptado otros que no les pertenecían o no eran característicos de su etnicidad: "no los vas a ver con plumas, tienen zapatillas mejores que las tuyas"; "no saben ninguna palabra en toba, ni en la comunidad lo hablan"; "las nenas bailan reggaetón... ¿reggaeton? ¿Eso los identifica?, ;no, eso nos identifica a nosotros!"; "lo típico no les llama la atención"; "están muy urbanizados, la cultura de ellos la tienen los grandes y los chicos nada". Estos hechos

\footnotetext{
${ }^{9}$ Nombra el barrio marginal de CABA del cual vienen.

${ }^{10}$ Fragmentos tomados de diversas entrevistas y charlas informales.
} 
colaboraban aportando "pruebas" acerca de una identidad cultural alterada o, por lo menos, permitían pensar en una gradualidad en la cual "tan tobas" no eran:

"Bueno, cuando empezaron a venir, el hecho, yo ya te he dicho que por ahí, si bien sus raíces, sus familias, sus abuelos eran tobas pero por ahí ellos... yo no los veo tan tobas. $O$ sea, son familias que han venido viste, como es de... ****11, toda esa zona. Claro y tienen esas costumbres que supongo yo que nada que ver con lo que es toba, el Chaco, allá donde va Patricia Sosa ${ }^{12}$, viste. Nada, me da la impresión de que nada que ver (...)"

(Entrevista a profesora ${ }^{13}$, noviembre de 2012)

Parecía que para ser "auténticos tobas" debían conservar intactas sus prácticas culturales pasadas, así como su lengua, y evitar todo tipo de "contaminaciones" en tanto rasgos prestados de sociedades ajenas o si se quiere modernas. En otras palabras, no se les otorgaba el derecho a cambiar, a ser sujetos históricos en relación con otros. Hecht (2008), Borton (2011) y García Palacios (2011) han relevado situaciones similares en contextos escolares de la provincia de Buenos Aires en los cuales una porción del estudiantado autoadscribe como toba/qom.

Así, para algunos/as docentes, los tobas no son tales o no existen en la escuela en tanto ese supuesto ideal. Podríamos decir, que estas concepciones se encuentran ligadas a los postulados clásicos de Crehan (2002) sobre la cultura, en los cuales la misma es caracterizada como: 1- un sistema que constituye un todo ordenado; 2- una entidad acotada y diferenciada y; 3relacionada íntimamente con lo tradicional en oposición a lo moderno. Es así como entonces, se termina por identificar una cultura con un pueblo determinado, asociado a un territorio concreto y caracterizado por una visión del mundo específica expresada a través de una lengua común. Esta concepción, por lo tanto, no permite ver la historicidad, fluidez y cambios culturales o hace que los mismos se vean como algo negativo y contaminante:

\begin{abstract}
“(...) el toba pensa que tienen otro... por lo menos que yo conozco, lo que he estudiado, son personas que tienen otro tipo de trabajo, son mucho más... no es la palabra hippie pero artesanos... son más buscavidas. Yo a estos los veo como más vivos. Vivos en el sentido de que no veo nada de toba. No veo el ritual de los tobas. El toba tiene distintos ritos, distintas actitudes. Acá yo no veo nada, yo veo como algo normal."
\end{abstract}

(Entrevista a profesora, julio de 2017)

\begin{abstract}
“(...) los tobas digamos, las leyendas de los tobas no son centenarias siquiera. Las leyendas de los tobas son de las primeras décadas del siglo veinte. El instrumento musical de los tobas es el violín de lata. Y la lata que yo sepa no es ancestral. Es de un contacto con el hombre blanco, llamale. Tienen una leyenda en la que el primer hombre se enfrenta con San Martin que es el único que lo puede vencer. Entonces, eso tiene que ver con la escolarización".
\end{abstract}

(Entrevista a directivo, noviembre de 2016)

Se asocia entonces, la idea de lo indígena con ciertas características y rasgos preestablecidos desde afuera, oponiéndolos a otros que se creen antagónicos o contrarios. De esta forma, se construye socialmente una dicotomía entre lo indígena, o en este caso "lo toba", y lo no indígena. Este último término de la dicotomía, presenta cierta superioridad o jerarquía con relación a su contrario, ya que históricamente dominó en su relación con el mismo, así como definió y nombró lo que debía, o no, considerarse indígena. Según Sousa Santos (2008), esta dicotomía obedecería a una de las formas en que se presenta el modelo hegemónico de

\footnotetext{
${ }^{11}$ Nombra una villa cercana a CABA.

${ }^{12}$ La cantante argentina Patricia Sosa, en 2008 fundó el grupo “Pequeños gestos, Grandes logros”, el cual tiene como objetivo ayudar a distintas comunidades del Impenetrable Chaqueño.

${ }^{13}$ Actualmente, esta profesora no se encuentra trabajando en la institución por haberse jubilado.
} 
racionalidad occidental que rige sobre el conocimiento de la realidad, denominado "razón metonímica". En la misma, gobierna la idea de totalidad y:

"como no existe nada fuera de la totalidad que sea o merezca ser inteligible, la razón metonímica se afirma como una razón exhaustiva, exclusiva y completa, aunque sea solo una de las lógicas de racionalidad que existen en el mundo y sea solo dominante en los estratos del mundo comprendidos por la modernidad occidental" (Sousa Santos, 2008:84).

En este sentido, todo aquello que escape a la dicotomía "indígena/no indígena", con las características que cada término implica, es considerado incomprensible o no existente para la totalidad hegemónica que la construye. Que los estudiantes y sus familias se reconozcan como tobas y, al mismo tiempo, hayan nacido en una villa en CABA, usen zapatillas Nike y bailen reggaeton, es cuestionable para esta forma de racionalidad. Desde esta perspectiva, la identidad cultural es percibida como una herencia, algo dado y preexistente a los individuos de lo cual no se puede escapar; así, la misma se naturaliza y se presenta como una esencia sobre la que es imposible influir (Cuche, 2007). Así, lo que se observa en las reflexiones que algunos miembros de las instituciones plantean, es una concepción en la cual:

"se trata de definir y de describir la identidad a partir de cierto número de criterios determinantes, considerados 'objetivos', como el origen común (la herencia, la genealogía), la lengua, la cultura, la religión, la psicología colectiva (la 'personalidad de base'), el vínculo con un territorio, etc." (Cuche, 2007:108)

Sin embargo, como sostiene Martuccelli (2009), las identidades no son "puras", todas son el producto de una construcción histórica en la cual diversos elementos son combinados, desafiando las "fronteras culturales". De esta manera, las identidades se conciben como construcciones sociales que se producen en las relaciones que oponen diversos grupos que entran en contacto (Cuche, 2007). Así, las distinciones étnicas, no dependen de la inexistencia de interacción, movilidad y aceptación social (Barth, 1976). Finalmente, lo que importa para definir la identidad de un grupo no es el conjunto de rasgos culturales distintivos, sino cuáles de esos rasgos son pensados por los miembros del grupo para afirmar y mantener una distinción cultural (Martuccelli,

\subsection{De la homogeneización de los estudiantes a la folklorización de sus saberes}

La diversidad cultural existente en las escuelas -así como la multiplicidad de experiencias de vida-, es reconocida por la totalidad de los/las docentes. La misma, en ocasiones es invisibilizada en pos de la igualdad del estudiantado y, en otras, es incorporada a las instituciones a través de la folklorización de ciertos "elementos" culturales. Estas prácticas, que se tornan contrapuestas y conviven en continua tensión -junto a las anteriormente analizadas-, persiguen el mismo objetivo: la inclusión de todos los niños, niñas y jóvenes en el sistema escolar. Se presentan entonces lo que parecieran ser las únicas dos alternativas a seguir: un esfuerzo por incluir la diversidad que termina siendo -quizás de forma involuntariaasimilacionista o un "rescate" de la diversidad que al folklorizarla genera segregación (Borton, Enriz, García Palacios, Hecht, 2011).

Así, si bien estas posturas se dan de manera distinta en ambas instituciones, en la escuela secundaria, la diversidad cultural presente en las aulas se ve desdibujada a través de la homogeneización de los estudiantes bajo el discurso "son todos iguales":

"En la escuela no se ve esa diferencia. Y los chicos tampoco la notan a la diferencia, porque es como que son todos iguales, entre ellos no se cargan por eso, no hay discriminación (...) para nosotros no es una problemática ... la diversidad cultural. (...)”, 
“(...) desde mi punto de vista no hay mucha diferencia como para tener que hacer un proyecto sobre la diversidad (cultural). Sino que como... como que ya los chicos vienen mentalizados a la adaptación del compañero o con los compañeros... y los profes tratamos de que no se sientan diferencias ni culturales ni de ningún tipo (...).

(Entrevista a profesora, julio de 2017)

En estos fragmentos de entrevista se observan dos cuestiones a resaltar, por una parte la asociación de la diversidad cultural con una problemática: la discriminación y, por la otra, la idea de que la homogeneidad genera de por sí igualdad. Asimismo, el discurso humanista que sostiene que todos son iguales, anula de inmediato el posible problema que acarrearía la diversidad. Es aquí donde vemos cómo aún se siguen filtrando prácticas y visiones que se presentan como resabios del viejo paradigma escolar.

Por otra parte, si bien no hay propuestas concretas a modo de proyectos, para integrar y poner en diálogo los conocimientos prescriptos por la escuela y aquellos que traen consigo los estudiantes producto de sus diversas experiencias de vida y cosmovisiones (lo cual es consecuente con esta visión en la que se sostiene que no existen diferencias entre ellos), se afirma que: "cuando surge algo nuevo, que van a alguna fiesta, los chicos comentan en la clase... lo que se hace en su pais, porque ellos como tienen otras vestimentas, otras comidas, otras costumbres, por ahi surge en las clases y se habla (...)". Sin embargo, en algunas ocasiones, son los docentes quienes proponen la incorporación en el aula de ciertos "elementos" culturales:

\begin{abstract}
Situación registrada: Observación de actividad para la feria del libro local.
Los jóvenes de $2^{\circ}$ año, están realizando en la clase de literatura, una actividad que les dieron ayer desde dirección (cuando estos se encontraban sin profesor a cargo) para presentar en la feria del libro local, en la que participan todos los colegios. Los jóvenes no recuerdan bien qué deben hacer así que llaman a la secretaria para que les vuelva a explicar la tarea. Al llegar, ella les explica que tienen que dividirse en grupos, cada uno con un libro de la colección "Con nuestra voz" 14 y elegir una frase en un idioma que les guste y su traducción en castellano. Luego, deben confeccionar pequeños libritos en donde vuelquen la frase en los dos idiomas. Ella les recuerda que esta actividad tiene que ver “con esto de la discriminación que es el lenguaje... el origen”. Les dice que en la tapa del librito deben poner el nombre de la escuela. Cuando le pregunta a los jóvenes cómo se llama la misma, ninguno responde. Ella les dice que la escuela se llama $* * * * 15$ y que tiene que ver con la actividad que están haciendo. Los libritos serán repartidos en la feria entre los invitados a modo de "souvenir". La secretaria se va y los estudiantes comienzan a realizar la actividad con la profesora de literatura, quien no interviene en el desarrollo de la misma.
\end{abstract}

(Nota de campo, agosto de 2016)

Vemos cómo esta actividad tiene de fondo un sentido más que importante: cuestionar la discriminación que sufren muchos estudiantes en relación con su origen y lengua madre. Sin embargo, el objetivo solo queda postulado y no se lleva adelante un diálogo en el cuál se problematice este hecho planteado por la docente. Al mismo tiempo, no se plantean estrategias para incorporar los posibles saberes de los jóvenes, ya que sólo se les solicita que copien de los

\footnotetext{
${ }^{14}$ Es una colección de 6 libros presentada por el Ministerio de Educación de la Nación que entrelaza textos plurilingües escritos en lenguas indígenas y en castellano por alumnos, alumnas, docentes y miembros de pueblos originarios de unas 120 escuelas de todo el país y agrupados en 19 universos lingüístico-culturales. Son producciones creadas para que circulen por toda la comunidad educativa como material para el conocimiento, el debate y el disfrute, y como recurso de enseñanza. http://eib.educ.ar/2015/11/con-nuestra-voz-textos-plurilingues.html

${ }^{15} \mathrm{El}$ nombre de la escuela hace referencia directa a los pueblos indígenas.
} 
libros de texto frases en cualquiera de los idiomas que aparecen. De esta manera, la actividad propuesta se transforma en la producción de una "manualidad", de un bonito "souvenir" para la feria; el cual pareciera cumplir la única función de ilustrar o representar el nombre de la escuela. Así, la tarea queda desprovista de sentido para los jóvenes. En este punto, coincidimos por lo tanto con Diez, Hecht, Novaro y Padawer (2010) en que, generalmente, las experiencias extraescolares de grupos étnicos o migrantes no aparecen objetivadas como saberes y muchas veces sucede que, si son reconocidas, se las traduce y resignifica desde el discurso pedagógico, convirtiéndolas en expresiones folklorizadas y devaluadas de la cultura.

Ahora bien, la escuela primaria, por su parte, presenta un proyecto institucional en el cual se sostiene que: "(se) apuntará a la diversidad cultural, para profundizar en las costumbres, conocer su pasado cultural, indagar en la riqueza de las familias, invitarlas a ser parte, hacerlas participar y conocer los relatos (mitos y leyendas) de sus lugares de origen.". Si bien el mismo se plantea como general con relación a la totalidad de la comunidad, las propuestas concretas encontradas sólo se dirigen a los estudiantes del barrio toba. Este hecho se encuentra en sintonía con el discurso que planteó una de las máximas autoridades del distrito escolar, en uno de los actos de la escuela primaria. En el mismo sostuvo que: "la presencia de la comunidad toba en la escuela, hace que las propuestas sean diferentes"; ante un auditorio colmado por familias bolivianas y ninguna a la que hacía referencia.

Esta preferencia, a la hora de pensar propuestas con relación a la diversidad cultural, puede deberse al hecho de que tanto este concepto como el de interculturalidad, en la presente Ley de Educación $\mathrm{N}^{\circ}$ 26.206, están relacionados con los pueblos indígenas. De esta manera, la interculturalidad que debiera incluir a todas las personas y atravesar a todo el sistema educativo, solo se enfoca en aquellos sujetos portadores de "marcas étnicas", generando formas de discriminación en el marco de una política que se supone inclusiva (Hecht, 2013).

Así, los dos proyectos encontrados fueron: el Centro de Actividades Infantiles ${ }^{16}$ que funcionó hasta el año 2016 y un proyecto áulico elaborado en 2012 y que continúa en la actualidad no de forma secuencial, como se pensó originalmente, sino retomando del mismo algunas cuestiones cuando se lo cree conveniente. Al indagar con la docente creadora sobre los fundamentos y objetivos del proyecto, su respuesta fue la siguiente:

\begin{abstract}
"Lo que pasa es que justo mi grupo, la mayoría, son alumnos tobas, por eso el director me sugirió que hiciera un proyecto con ellos para... ya que la mayoría eran tobas para que ellos sepan sus raíces porque la mayoría de ellos está muy urbanizados (...) Entonces, más o menos, para hacer una recorrida de sus antepasados, ¿no? Cómo vivían, cómo eran sus costumbres, por qué vinieron acá, por qué algunos se quedaron allá, cómo viven acá... Porque en realidad ellos no conocen mucho (...) También, que sepan que hay otra lengua, ellos hablan la lengua qom, que solamente los mayores la hablan (...) Esa es la idea, que sepan cómo vivían, cómo han evolucionado, cómo han emigrado y este... sentirse orgullosos también de sus raíces; que también está el tema de la discriminación, entonces hablar mucho sobre eso. Este... y leerles leyendas, también es un espacio de recreación... leyendas tobas, cuentos tobas. Este, mostrarles su cultura, ¿no?"
\end{abstract}

(Entrevista, octubre de 2012)

Es interesante reflexionar acerca del objetivo del proyecto, el cual podríamos decir que se resume en la última oración de la respuesta: "mostrarles su cultura", tanto a ellos mismos como a sus compañeros no tobas. Según la institución, los niños y niñas tobas, producto de su urbanización, no conocen sus raíces ni su cultura -situación paradójica ya que si se la reconoce como "su cultura" sería evidente que los "portadores" de la misma la conozcan-; por lo tanto, es necesario enseñarles "cómo vivían, cómo han evolucionado, cómo han emigrado (...)".

${ }^{16}$ Este programa funcionaba los días sábados en la escuela. Además de darse clases de inglés, apoyo escolar y juegos recreativos, se daba un taller de artesanía originaria y canto, a cargo de un referente del barrio toba. 
Entonces, es la escuela a través de este proyecto, la que repondría aquellos conocimientos que quedaron en el camino producto de lo que se considera una "mezcla" perjudicial17.

Así, los contenidos del proyecto áulico, a pesar de que se refieren a las costumbres, leyendas, lengua, formas de vida actuales y de los antepasados; no son el producto de charlas con los adultos ${ }^{18}$ de la comunidad para indagar acerca de sus saberes o conocer qué cuestiones (y de qué forma) consideran que deben ser transmitidas a través de la escuela (o no). De esta manera, el tema de los contenidos queda como pura competencia de los especialistas que se graduaron para la tarea de enseñar, transformándose así en propietarios de un componente fundamental de la práctica educativa: la elección de los contenidos (Freire, 1993). Así, aunque no sea la intención, resurge la imagen de la escuela como "el templo del saber", la cual no tiene ninguna conexión con lo que no sea el templo (Jauretche, 1967). En estas condiciones, al tratar la escuela de enseñarle a los niños tobas su cultura o sus "raíces" (desde las mejores intenciones y deseos por dar lugar a la diversidad cultural en el aula), les niega a los mismos y a los adultos de la comunidad, el estatus de sujetos de saber. Es aquí también, donde nuevamente se filtran concepciones del viejo paradigma escolar.

Finalmente, a lo largo de este apartado, pudimos observar cómo en la escuela conviven y se tensionan continuamente distintas alternativas para "incluir" la diversidad en las aulas. A pesar de que las políticas van desde el reclamo de la igualdad al reconocimiento de las diferencias (Juliano. D, 1997), el cambio de paradigma en educación es relativamente reciente, "colándose" ciertas nociones de las viejas políticas homogeneizadoras, que se pretenden dejar atrás. En este sentido, es importante que las prácticas a favor de la igualdad no nieguen la diversidad, así como las prácticas que atienden a la diversidad no mantengan ni enmascaren la desigualdad (Hecht, 2015).

\section{Palabras finales}

En este artículo se presentaron tres formas de abordaje de la diversidad cultural en las aulas: el señalamiento como forma de normalizar la diversidad, el esencialismo como marco para autenticar las identidades y, finalmente, el tratamiento folklorizado o inexistente de los saberes y experiencias de los estudiantes. Pudimos ver entonces, cómo algunas formas de ver, pensar y actuar en relación con la diversidad cultural coincidían entre sí tratando de enmarcarse -a su manera- en el paradigma educativo contemporáneo y, cómo otras, parecían filtrarse del viejo modelo. Ahora bien, en el actual paradigma escolar que tiene como objetivo la inclusión de todos los niños, niñas y jóvenes - quizás por su relativa novedad-, los conceptos de igualdad y diversidad entran en continua tensión, interpretándose en ocasiones como contrapuestos. Son los docentes, quienes día a día, bajo condiciones laborales poco favorables, deben pensar prácticas y estrategias concretas para lograr la inclusión de la diversidad cultural en un sistema escolar que no les brinda las herramientas necesarias para hacerlo y que, históricamente, abogó por la homogeneidad del estudiantado como sinónimo de igualdad. En este contexto y en la vorágine de tener que dar respuestas a las demandas de inclusión, como hemos visto a lo largo de este trabajo, surgen prácticas, discursos y representaciones, que en algunos casos mantienen una misma línea y en otros no.

Así, en muchas ocasiones, con el objetivo y entusiasmo por valorizar las diferencias, normalizarlas y recuperar las voces de los estudiantes, se olvida que tanto dentro de la escuela como fuera de ella existen relaciones de poder y, por ende, de desigualdad en las cuales muchos de ellos y sus familias se encuentran inmersos. En dichas relaciones, son considerados grupos raciales inferiores $y$, en torno a diferentes palabras -como indio, boliviano, etc. - , se crean

\footnotetext{
17 Vemos así cómo esta propuesta se encuentra en sintonía con las inquietudes que algunos docentes tienen con respecto a la identidad étnica de estos estudiantes.

${ }^{18} \mathrm{El}$ proyecto presenta una entrevista al presidente de la comunidad.
} 
estereotipos negativos que intentan definirlos desde la generalidad y segregarlos del grupo social más amplio. Es entonces - cuando la valorización de la diversidad cultural queda descontextualizada de un marco más amplio que el meramente escolar-que los estudiantes se sienten expuestos y no pueden vivenciar de forma positiva ciertas actividades, preguntas o discursos escolares que se presentan como tales. Asimismo, en esta revalorización de la diversidad cultural, se tienden a cristalizar los grupos étnicos a través de la exaltación de un pasado que se presenta como la esencia de los mismos. Esta visión les niega la capacidad histórica que tienen todas las sociedades de transformase y, al mismo tiempo, invisibiliza las causas pasadas y presentes de la desigualdad en la que se encuentran muchos.

Junto con estos tratamientos, encontramos otros que parecen colarse como resabios del viejo paradigma escolar. Así, la igualdad de los estudiantes se obtiene desdibujando la diversidad presente y homogeneizándolos. El "tratar a todos por igual" o pensar que "son todos iguales" se ve como anulador directo de la diversidad que podría ser posible fuente de problemas como la discriminación. La diversidad cultural se transforma entonces en igualdad, a través de la invisibilización de la misma. Asimismo, la escuela continúa siendo el sitio en el cual se encuentran los saberes válidos. Ella pretende contener hasta el saber que por derecho le corresponde a otros, despojándolo en el proceso de todo contexto y significado. En cuanto a las experiencias extraescolares y saberes que los estudiantes -en ocasiones- traen a las aulas, son retomados de modo anecdótico u ornamentario.

El desafío es complejo: deshacerse por completo del viejo paradigma homogeneizador para valorar la diversidad cultural -dialogando con distintos saberes y formas de estar, ver e interpretar el mundo- en un contexto social más amplio, el cual continúa siendo hostil con "los otros" y en donde solo recientemente han comenzado a plantearse discursos a favor de una "patria grande".

\section{Bibliografía}

BALIBAR, E. (1990): “¿Existe un neoracismo?”. En Wallerstein y Balibar Raza, Nación y Clase. IEPALA. Madrid

BARTH, F. (1976): “Introducción”. En Los grupos étnicos y sus fronteras. Fondo de Cultura Económica. México

BORTON, A. (2011): "Representaciones docentes sobre el silencio como estilo comunicativo en una escuela en situación de interculturalidad". En Novaro, G (Comp.) Niños indígenas y migrantes. Tensiones identitarias, experiencias formativas y procesos de escolarización. Biblos. Buenos Aires.

BORTON, A., N. ENRIZ, M. GARCÍA PALACIOS y A. C. HECHT (2010): "Una aproximación a las representaciones escolares sobre el niño indígena como sujeto de aprendizaje". En Silvia Hirsch y Adriana Serrudo (Comps.) La EducaciónIntercultural Bilingüe en Argentina. Identidades, lenguas y protagonistas. Novedades Educativas. Buenos Aires.

CREHAN, K. (2002): “Antropología y cultura: algunas hipótesis". En Gramsci, Cultura y Antropología. Bellaterra. Barcelona.

CUCHE, D. (2007): "Cultura e identidad". En La noción de cultura en las ciencias sociales. Nueva Visión. Buenos Aires.

DIEZ, M.L y G. NOVARO (2014): "Continuidades y discontinuidades entre sistemas educativos nacionales: la educación en Bolivia y en Argentina desde una perspectiva intercultural". En Villa, A.I y Martinez, M.E (Comps.) Relaciones escolares y diferencias culturales: la educación en perspectiva intercultural. Noveduc. Buenos Aires. 
DIEZ, M. L., A. C. HECHT, G. NOVARO y A. PADAWER (2010): "Interculturalidad y educación. Cruces entre la investigación y la gestión”. En Novaro, G (Coor.) Niños indígenas y migrantes. Tensiones identitarias, experiencias formativas y procesos de escolarización. Biblos. Buenos Aires.

DIEZ, M. L. (2004): "Reflexiones en torno a la interculturalidad". En Cuadernos de Antropología Social, $\mathrm{N}^{\circ}$ 19. Facultad de Filosofía y Letras. Universidad de Buenos Aires.

FREIRE, P. (1993): Pedagogía de la esperanza. Siglo XXI. México.

GAVAZZO, N. (2013): "No soy de aquí, ni soy de allá... Alterización y categorías de identificación en la generación de los hijos de inmigrantes bolivianos y paraguayos en Buenos Aires". Revista Claroscuro, 0 (12), 1-23.

GARCÍA PALACIOS, M, A. C. HECHT Y N. ENRIZ (2015): "Pueblos indígenas y escolarización: los usos del concepto de interculturalidad en el debate educativo contemporáneo". Educación, Lenguaje y Sociedad, 12 (12), 1-25.

GARCIA PALACIOS, M. (2011): "Religión y etnicidad. Procesos educativos e identificaciones de los niños y niñas de un barrio indígena urbano.”. En Novaro, G (Comp.) Niños indígenas y migrantes. Tensiones identitarias, experiencias formativas y procesos de escolarización. Biblos. Buenos Aires.

HECHT, A.C. (2015): "Educación intercultural bilingüe en argentina: un panorama actual". Ciencia e interculturalidad, 16 (1), 20-30.

HECHT, A. C. (2013): “(In) definiciones de la escolarización en contextos de diversidad etnolingüística. Análisis de la EIB en Argentina". Século XXI Revista de Ciências Sociais, 3 (1), 185-211.

HECHT, A. C. (2008): "Lengua e identidad de niños indígenas en contextos urbanos". Alteridades, 36 (18), 145-159.

HECHT, A. C. (2007): "Pueblos indígenas y escuela. Políticas homogeneizadoras y políticas focalizadas en la educación argentina”. Políticas Educativas, Campinas, 1 (1), 183-194.

JAURETCHE, A. (1967): La colonización pedagógica. Conferencia del $1^{\circ}$ curso de temporada de la Universidad Nacional del Nordeste- República Argentina. Resistencia, Chaco.

JULIANO, D. (1997): "Universal/Particular, un falso dilema". En Globalización e identidad cultural. Ciccus. Buenos Aires.

MARTUCCELLI, D. (2009): "Universalismo y Particularismo: mentiras culturalistas y disoluciones sociológicas". En Diversidad cultural, desigualdad social y estrategias de políticas educativas. IIPE UNESCO. Buenos Aires.

NOVARO, G. (2011): "Niños migrantes y escuela: ¿identidades y saberes en disputa?". En Novaro, G. (Comp.) Niños indígenas y migrantes. Tensiones identitarias, experiencias formativas y procesos de escolarización. Biblos. Buenos Aires.

REBELlATO, J. L. (2010): "Paulo Freire: educación y proyecto ético-político de transformación”. En Korol, C. (Comp.) Pedagogía de la resistencia. Cuadernos de Educación Popular. Ediciones Madres de Plaza de Mayo-América Libre. Ciudad Autónoma de Buenos Aires.

ROCKWELL, E. (2009): "Reflexiones sobre el trabajo etnográfico". En La experiencia etnográfica. Historia y cultura en los procesos educativos. Paidós. Buenos Aires.

SOUSA SANTOS, B. (2008): Conocer desde el Sur. Para una cultura política emancipatoria. CLACSO-CIDES-UMSA. La Paz.

SINISI, L. (1999): "La relación nosotros-otros en espacios escolares 'multiculturales'. Estigma, estereotipo, racialización”. En Neufeld, M. R. y Thisted, J. A. (Comps.) De eso no se habla. Los usos de la diversidadsociocultural en la escuela. EUDEBA. Buenos Aires.

SZULC, A., A. C. HECHT; M. C. HERNÁNDEZ, P. LAEVY, M. VARELA, L. VERÓN, N. ENRIZ Y M. HELLEMEYER (2009): "La investigación etnográfica sobre y con niños y niñas. Una mirada desde la antropología.". En el XXVII Congreso de la Asociación Latinoamericana de Sociología. Buenos Aires, Argentina. 
TARUSELLI, M.E (2017): “'Yo no soy puro boliviano, soy mitad argentino, mitad boliviano':

Construcciones identitarias de niños, niñas y jóvenes de origen boliviano en una escuela rural de argentina" (manuscrito inédito)

THISTED, S. (2014): "Políticas, retóricas y prácticas educativas en torno a la cuestión de las "diferencias". Itinerarios de un siglo largo en el tratamiento de la cuestión de migrantes e indígenas". En Villa, A.I y Martinez, M.E (Comps.) Relaciones escolares y diferencias culturales: la educación en perspectiva intercultural. Noveduc. Buenos Aires.

\section{Marcos normativos}

Constitución Nacional de 1853

Constitución Nacional de 1994

Ley de educación $\mathrm{N}^{\circ} 1420$ de 1884

Ley de educación $\mathrm{N}^{\circ} 26.206$ de 2006 